\title{
9 Impacts on mobility in an ageing Europe
}

\author{
Vasco Reis and André Freitas
}

\begin{abstract}
An elderly person is a person aged 65 or over according to the definition of the European Union. At EU level, about one fifth of the population is elderly. Life expectancy has been increasing consistently in the last few decades. The impact of this trend on overall mobility demand is yet unclear, in part because elderly people are increasingly mobile. Even so, the natural ageing process is accompanied by a gradual deterioration in physical and psychological traits.

The increasing digitisation of mobility systems is another relevant aspect. The fast pace of technological development is known to exclude those less tech-savvy, which is common among elderly people. Finally, these demographic changes pose substantial challenges to authorities financing public transport services.
\end{abstract}

\section{Introduction}

There is no consensus regarding the definition of an elderly person and the World Health Organisation (WHO) stresses that it should not be regarded as a fully uniformed concept as it is westernised and may not fit some local realities, namely those related to poverty (WHO 2016). Nevertheless, the common definition accepted within the EU refers to an elderly person as a person aged 65 or over (young-old) and a very old person as a person aged 85 or over (old-old) (Eurostat 2017a, OECD 2018). The former group refers to those people who continue to have an active and independent life, normally after retirement. The latter refers to those less active people (due to some sort of disability, either cognitive or physical) and who require help from other people.

The following graph conceptualises mobility decline over the years, highlighting two segments of elderly people: young-old and old-old (Figure 9.1). The evolution from one to another segment is gradual and there is no determined age. A possible estimation can be obtained from the indicator of healthy life years at the age of 65 . At EU level, this indicator is on average a decade. Hence, the segment of the young-old may range between 65 and 74 years and the segment of the old-old is after 75 years. A second important 


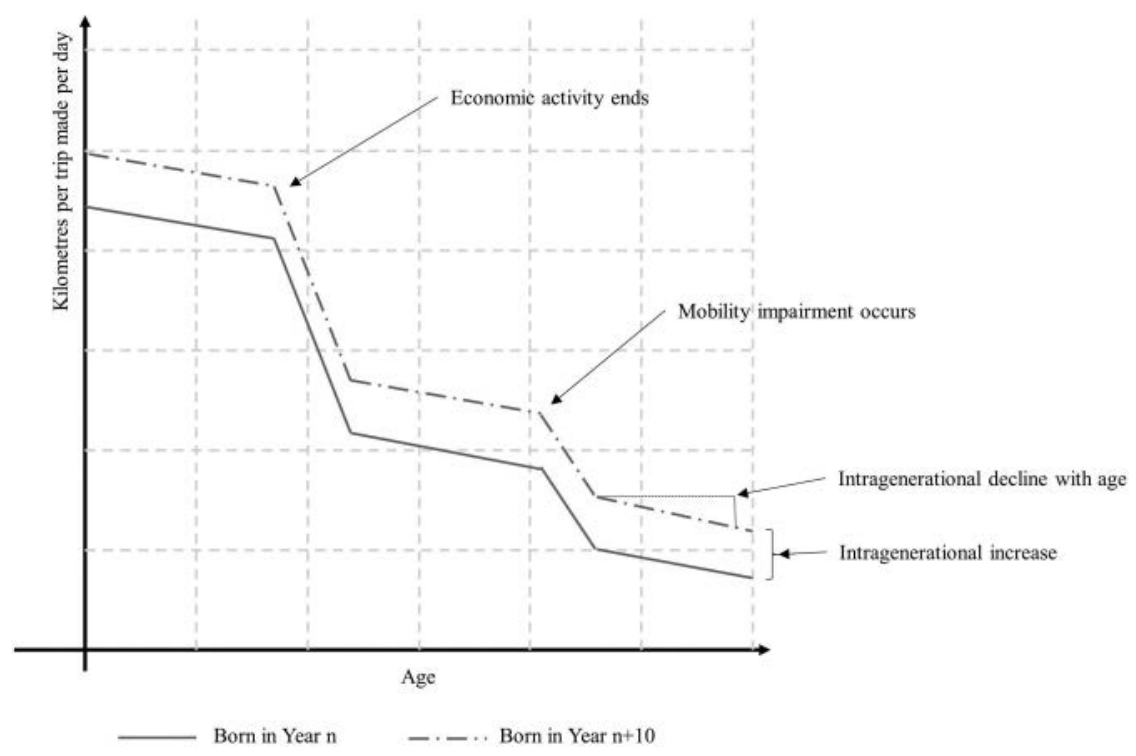

Figure 9.1 Conceptual model of mobility while ageing.

Source: Authors, based on Zmud et al. 2017.

insight from the graph is the representation of intergenerational mobility gains. The young generation of elderly people has more enhanced mobility than older generations, remaining active and mobile for more years. This is the consequence of improvements to social care services or the medical and health support system. Mobility systems must thus be planned to cope with the changing needs of these new generations of highly active and mobile elderly.

Overall figures from the EU-28 show that about one fifth of its population is aged 65 and above. ${ }^{1}$ Furthermore, it is in rural regions that older people account for a higher proportion of the population (Eurostat 2017a). Most of the areas with high proportions of elderly persons are not only rural but sometimes also remote. Nevertheless, this reality is not so widespread as, for example, in some areas of Eastern Europe, namely Poland (Eurostat 2017a). Life expectancy has been increasing consistently in the last few decades and 2015 data indicate a life expectancy at birth of around 80 years, given that women have a life expectancy six years higher than men.

However, as life expectancy at birth is a fluctuating value, it is also interesting to consider life expectancy at the age of 65 . This figure was estimated to be around two decades (Eurostat 2017a). The higher life expectancy for women seems to have an impact on the proportion of women living alone aged 65 and over, which is higher than men (Eurostat 2015). Globally, in 2013 elderly citizens represented $40 \%$ of single-person households in the EU 
(Eurostat 2015). An important related aspect concerns the healthy life years at the age of 65 . This influences several of the previously discussed characteristics, including the level of activity and mobility, employment or dependency ratios. According to Eurostat, on average a European has around a decade of healthy life after the age of 65. However, there are substantial variations among member states.

The growing level of access to digital tools and ICTs among older citizens should also be noted. More and more elderly people use the internet and digital technologies, both due to the natural aging of younger generations who have used the internet for quite some time or simply because people learn new skills. Even so, this segment remains somewhat wary about technology, particularly where computers and the internet are concerned. In 2016, almost half of the elderly population in the EU-28 used the internet at least once a week. In 2006, it was just a small proportion (Eurostat 2017a).

The increasing proportion of elderly people is one of the main challenges facing the EU in the next decade, both socially and economically. The growing technological capabilities need to be considered in any policy design, no matter what field. Policy planning and design for anything longer than the short term must consider the fast-growing digital capabilities gained from one generation to the next.

\section{Mobility related characteristics}

National populations are ageing as longevity increases. The impact of this trend on overall mobility demand is as yet unclear, in part because increasing longevity means that the characteristics of particular age cohorts change. By way of example, over time older women hold driving licenses, while frailty and loss of independent mobility tend to occur later in a longer life course (Metz 2013).

According to a recent IFMO study (Zmud et al. 2017), as the proportion of elderly increases, and the relative proportion of adults decreases, the effects both on demand and supply of transport can be considered relevant. Conversely, in rural and less developed areas, elderly people tend to be less mobile, due to a poor offer of transport services and less accessible transport infrastructure, coupled with physical and cognitive impairments.

Elderly people are increasingly mobile. Often people in their 60s (and even older) can be seen (and see themselves) as still very active, maintaining a very high overall activity level, traditionally not associated with their age. Financial resources, overall health and mobility do have an impact on those (self)perceptions (Samek Lodovici et al. 2012, Institute for Mobility Research 2013).

A higher life expectancy, better overall health and increased inclusion in the workforce are factors supporting this increased activity. Furthermore, factors like pensions, changing living arrangements and social connections combined with more varied and better transport options are related to the 
amount of travel and mode choices of older people (Institute for Mobility Research 2013). It can thus be perceived that there is growing transport demand from elderly people due to better health conditions, improved travelling solutions, more foreign-language skills and travelling lifestyles (Samek Lodovici et al. 2012). This trend may also lead to more cycling within this age group. For example, in Belgium, elderly people are early adopters of e-bikes (CIVITAS 2016).

Moreover, walking and cycling are seen across the EU as increasing activities among elderly citizens who wish to maintain active lives, as these are not only easy to maintain and accessible means of transport, but also associated with advantageous health outcomes (McDonald et al. 2013).

As elderly people are currently increasingly more active until later periods in their lives, it can be suggested that public transport may be crucial in maintaining active lifestyles even in cases where driving is no longer a possibility. Public transport is therefore very important as a support for older people's quality of life, improving their sense of freedom and autonomy (even more so in rural areas), guaranteeing access to basic services and decreasing social isolation (Shrestha et al. 2017).

Recognising the relevance of this age segment and its mobility, the European Commission funded the GOAL (Growing Older and staying mobile) project, within which five profiles for elderly people were defined - 'Fit as a Fiddle', 'Hole in the Heart', 'Happily Connected', an 'Oldie but a Goodie' and 'Care-Full' (based on data available through the SHARE database, survey of Health, Ageing and Retirement in Europe - http://www.share-project. org). Figure 9.2 shows the age and activity level of the profiles of older people as described in GOAL. These profiles vary in several characteristics, namely age, general health conditions, mental capabilities, reasons for travel, driving skills, need for assistance, among others (McDonald et al. 2012).

The scope of GOAL included the study of the requirements of public transport for older people, specifically addressing four main areas: affordability, availability, accessibility and acceptability.

Some segments of elderly people do experience mobility limitations caused by significant life-changing events such as increasing cognitive problems and physical impairments. The transition from using a car to using other transport modes will eventually occur for most people, namely for health or economic reasons or simply the responsibility of driving becomes too great. Nevertheless, such a transition will be very different according to personal conditions and experiences, and considering different social contexts (McDonald et al. 2013).

Moreover, travel behaviours and mobility patterns change as a person ages. According to the Mobilität in Deutschland survey (2008), cited by Hounsell and colleagues (Hounsell et al. 2016), ageing (after 55) is associated with more walking, less driving and more usage of public transport (especially after 75). Consequently, this segment of the population is associated with fewer journeys when compared to younger adults and will likely 


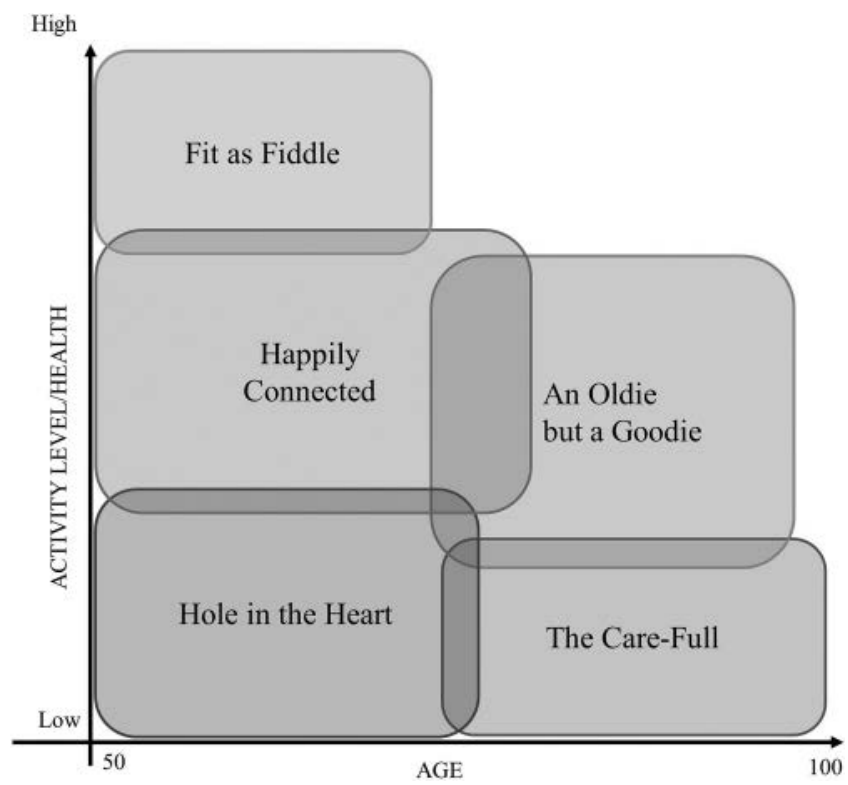

Figure 9.2 Age and activity level of the profiles of older people.

Source: Authors, based on McDonald et al. 2013.

change their transport mode (Hounsell et al. 2016). Notwithstanding, the preferences of the elderly are changing. By way of example, in the United Kingdom, the option of walking has been decreasing for some decades (McDonald et al. 2012).

Regardless, the mobility of older people is likely to be dependent on an adequate supply and appropriate quality of public transport services (Hounsell et al. 2016). Mollenkopf and Flaschenträger (2001, cited in Hounsell et al. 2016) found that "almost all older persons, regardless whether they participate in walking, cycling, driving or using public transport, suffer from the tighter and more aggressive traffic".

The reduction in travel in older age groups may also simply arise as a result of their smaller presence in the workforce. Therefore, older Europeans tend to use urban public transport mostly for leisure activities (shopping, visiting friends and relatives) to take children to school and to other after-school activities and to access healthcare services. The preservation of such activities is related to the availability of public transport, which is therefore of importance for the quality of life of the elderly (McDonald et al. 2013).

Often, changes in mobility patterns will be related to the increasing difficulty in overcoming different barriers that might occur due to the ageing process. Older people may face physical, psychological and economic 
barriers to travel. These may include diminished motor, sensory and cognitive abilities (ECMT 2002). For example, regarding public transport, transport-related barriers can be linked to difficulties in reaching bus stops or getting in and out of vehicles to the fear of falling or concerns with personal security, or even difficulties in reading timetables and destinations. Improvements in public transport are therefore critical to an "age-friendly" approach, especially among rural segments, supporting an independent life and access to basic services and helping decrease social isolation (Hounsell et al. 2016).

\section{Mobility-related disadvantages}

Age-related changes and their consequences for mobility include decreased flexibility and strength, impairment of visual function, increased vulnerability to bone fracture. As such, older people are more prone to be affected than other age groups by stressors like high levels of traffic density and flow, as well as the fact that some drivers lack consideration for other road users. Therefore, the provision of appropriate quality public transport is paramount for the mobility of older people.

It is well known that the elderly population has significantly increased its average mileage per year and has a high motorisation rate. There has been significant growth in kilometres travelled per day by seniors in the study countries (Institute for Mobility Research 2013):

- $70 \%$ increase in England from 1982 to 2012;

- $40 \%$ increase in Germany from 1982 to 2012;

- $40 \%$ increase in the United States from 1983 to 2008; and

- $30 \%$ increase in Japan from 1987 to 2010.

Nevertheless, for each additional year of age, senior mobility declines overall at about one kilometre per person per day. In such a context, driver attitude and driving behaviour are some of the factors that can influence this segment's transition to public transport (Shrestha et al. 2017).

Overall, whilst mobility indisputably declines with age, successive generations are nevertheless starting their declines at higher levels of mobility, for which the main contributor is car ownership. In Germany, for example, the percentage of elderly people owning a car has tripled since the mid-1980s more than for any other age group (Institute for Mobility Research 2013). But whilst car ownership rates for older people has increased, car use actually decreases with age, probably due to an increasingly challenging driving environment.

These changes may also be connected with travelling for tourism purposes. Elderly people represented around one fifth of EU tourists, which is still lower than the share of the EU population that this segment represents (Eurostat 2017b). On average, almost half of EU elderly people travel 
for tourism purposes and above one quarter travel to another EU member state. Elderly people tend not to be employed and so are able to benefit from discount and budget trips offers. Data on this provide some significant consequences in terms of externalities. Safety issues and accident rates (report accident rates by age group) in relation to declining driving capabilities are perceived as one of the reasons not to drive. In fact, the highest proportion of accidents involving older drivers and for which they are responsible is somehow related to perception and decision-making issues (Verhaegen 1995). The GOAL project identified the causes of accidents with physical injury involving elderly people in the old-old segment (Figure 9.3). It can be seen that the use of the wrong way, together with other driving errors account for more than one third of cases. Moreover, European accident data show that older car occupants, pedestrians and cyclists have significantly higher risks of severe and fatal injuries. Male elderly citizens seem to be particularly at risk when it comes to cycling accidents, while women have an increased risk as pedestrians (Wisch et al. 2017).

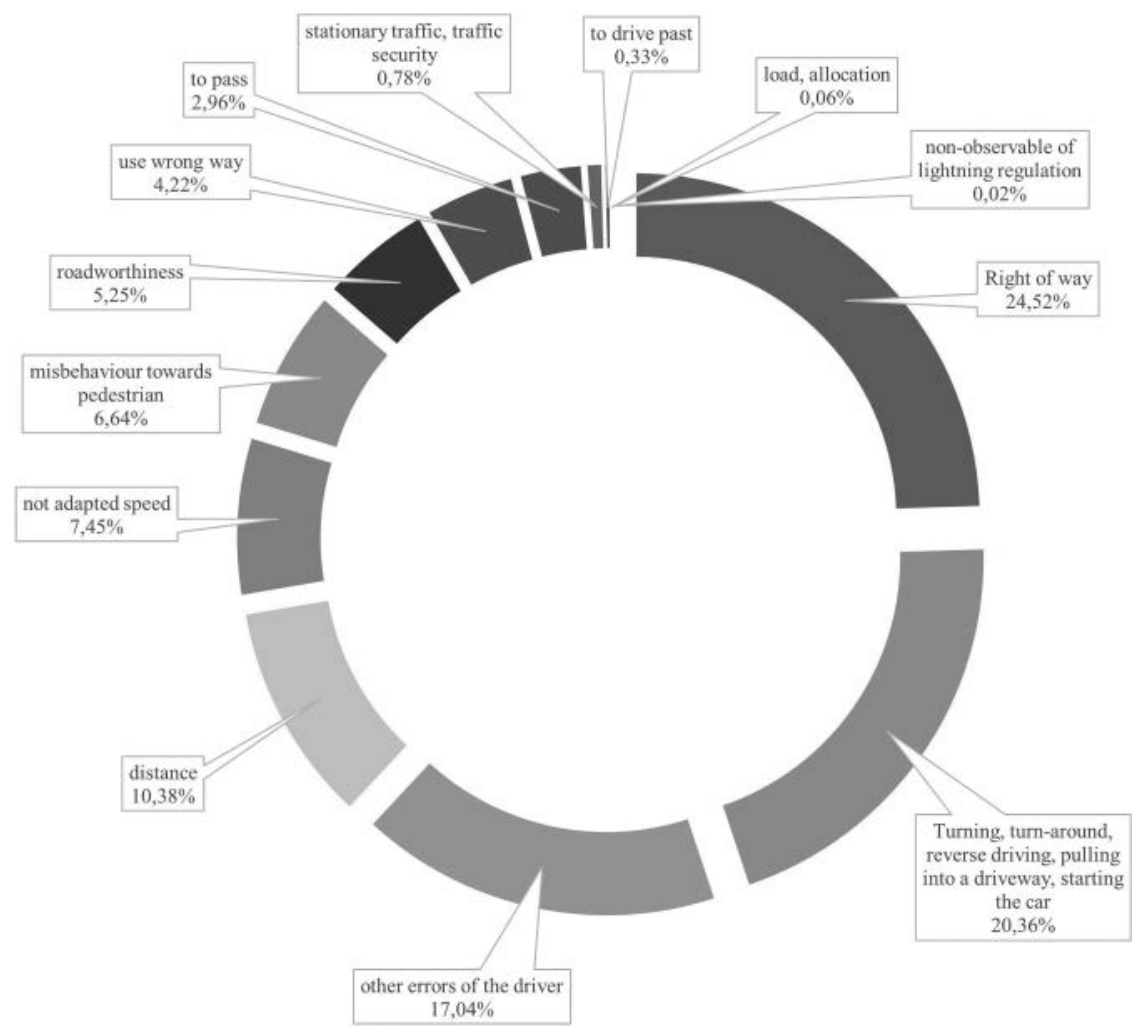

Figure 9.3 Causes of traffic accidents with physical injury for age group 75 and older.

Source: Authors, based on McDonald et al. 2012. 
Despite the safety-related issues, high levels of car ownership can make transitions to other means of transportation that could somewhat compensate for increasing cognitive problems and physical impairments difficult. In fact, some elderly people who have previously relied mostly on their car can find it very challenging to transition from driving to using public transport (Shrestha et al. 2017).

Independently of the mode, accessibility is a key issue for older people using transport systems. Regarding public transport, relevant issues are the location of bus stops in relation to the trip origin and destination(s), the quality of the infrastructure for the walking sections of the journey and the accessibility of the vehicles themselves (e.g. whether they feature a low floor). Even in the light of recent progress improving accessibility for previously excluded segments of the population within the EU, about " 10 to $20 \%$ of European citizens (namely people with disabilities and older people) still face barriers and reduced accessibility to transportation" (Shrestha et al. 2017, 347). For older people, it is essential to guarantee the provision of public transport within the reach of people's origins and destinations, with adequate service times and frequencies, which may assume the form of special transport services if user experience reduced physical abilities.

The reluctance that some older people may show in using public transport may be related to their health, but also because of difficulties caused by the system itself. In fact, those who used public transport their entire lives are usually more prone to using different transport alternatives. On the contrary, those who mostly relied on their own car as their main transport mode tend to see public transport as complicated and inconvenient, mostly due to their lack of previous experience (Adler and Rottunda 2006).

Considering the potential impacts of injuries for older people, safety is a serious concern for this age group. The likelihood of a longer recovery period and a greater psychological impact than a younger person in a similar incident play a significant role in this perception. These may be the reasons why older people worry about their safety and are reluctant to take public transport or use bikes, for example, together with the fear of crime or falling over and becoming injured (Shrestha et al. 2017). On the other hand, slow journey times might not be seen as a barrier for older people when compared with other segments of the population (Transport for London 2014).

\section{Multiple socio-economic disadvantages}

Elderly people have more critical socio-economic characteristics than younger generations, owing to their position in the labour market and health conditions. The socio-economic characteristics of this group should be considered with particular attention on several factors, most of which are interrelated: household income, working status and disability or impairment affecting travel. Household income can be strongly influenced by 
retirement (which in many cases represents a lower net monthly income), loss of a spouse or illness, just to name a few.

The percentage of older people living alone in the EU (almost one third) highlights some of the increased susceptibility of this segment, as it represents not only lower incomes, but, most likely, isolation. Moreover, the percentage of older people living alone may represent a strong disadvantage for this segment's mobility (Eurostat 2015).

Mobility impairments are also associated with declines in mobility. Despite increasing life expectancy, this does not necessarily represent an extended quality of life, especially in light of the increasing prevalence of stressors such as smoking, diabetes, obesity and low levels of exercise. These conditions can significantly increase the need to allocate a greater share of household spending to rising healthcare costs, contributing to a reduction in discretionary household income and dwindling wealth accumulation.

The risk of poverty among elderly people is associated with decreased mobility and restrictions on access to transport. These older citizens will make significantly fewer trips and cover less distance daily than people with higher incomes. For example, for disadvantaged older women in low-status residential areas, trips will mostly cover their local residential environment (Giesel and Köhler 2015).

Hence, affordability is also a relevant topic for many elderly people, especially for those with less available income in retirement. In a context of more limited resources, the cost of travelling will become a major barrier for many old people to travel as often as they would like. In extreme cases, the cost of transport can represent a barrier to access basic and necessary services (hospitals, supermarkets, pharmacies) (Shrestha et al. 2017). For older people in such situations, who usually have more time and less money, travel costs become more important, leading to the choice of cheaper alternatives that require longer travel times.

\section{Conclusions}

Elderly people's characteristics will keep evolving considerably fast. It is likely, for example, that activity levels among elderly people will increase in the future. Life expectancy will continue to increase and it can be expected that senior people will remain employed for longer, taking on second careers or volunteer activities. These changes will have an impact both in economic and psychological terms. Nevertheless, ageing cannot be stopped and senior people will, sooner or later, face physical difficulties that will be accompanied by certain inevitabilities. Therefore, it is possible at the same time to find factors that support as well as hinder mobility patterns alongside the ageing process. It must be recognised that today's seniors are in fact a very diverse population segment and that therefore not all people will react in the same way. Furthermore, as societies evolve, so do mobility and travel patterns, associated with a high level of uncertainty. 
Another relevant aspect is that mobility systems must ensure digital inclusion. The fast pace of technological development is known to exclude those less tech-savvy, which is common among elderly people, notably in the group of the old-old. This situation is paradoxical in the sense that new mobility solutions, such as autonomous vehicles or ride hailing services, can help precisely those with mobility impairments, which appear once people age. Yet, due to lower levels of digital literacy, those who could benefit the most are at risk of being kept at bay. Such a vicious circle may be, and is being, interrupted when engaging the social networks of senior citizens. Younger people (e.g. relatives, friends, neighbours) can assist the elderly in using new mobility solutions. The benefits should largely go beyond the field of mobility, as they also contribute to nurturing the social network of the elderly, which is at risk of decaying over time.

Demographic changes already pose substantial challenges to authorities financing public transport services and the pressure to find adequate solutions will further increase. There is still a research gap regarding such solutions. In fact, in the vast majority of countries, elderly people have access to several travel discounts. In some cases, as in the UK, retired people are granted free bus travel, with only minor restrictions usually related to peak periods.

As the population pyramid gets inverted, the share of subsidised public transport users is likely to increase, whereas passengers paying the full price will diminish, raising new funding challenges that will have to be dealt with in the short term by the relevant stakeholders. This phenomenon is even more striking in rural areas where the share of older people is higher than in urban areas.

\section{Note}

1 It should however be mentioned that such proportions do vary significantly across Member States. In 2016, the three highest shares were found in the central Greek region of Evrytania (30.7\%), the north-western Spanish region of Ourense $(30.7 \%)$ and the West Flanders municipality of Veurne in Belgium (30.2\%) (Eurostat 2017a).

\section{References}

Adler, Geri, and Susan Rottunda. 2006. "Older adults' perspectives on driving cessation." In Journal of Aging Studies 20, no. 3, 227-235. https://doi.org/10.1016/j. jaging.2005.09.003.

CIVITAS. 2016. "CIVITAS thematic policy note - transport poverty." https:// civitas.eu/sites/default/files/civitas_policy_note_transport_poverty.pdf. Accessed 2 April 2020.

ECMT. 2002. "Transport and ageing of the population." European Conference of Ministry of Transport. https://read.oecd-ilibrary.org/transport/transport-andageing-of-the-population_9789264187733-en\#page12. Accessed 2 April 2020. 
Eurostat. 2015. "People in the EU. Who are we and how do we live?" https://ec.europa. eu/eurostat/statistics-explained/index.php/People_in_the_EU_\%E2\%80\%93_ who_are_we_and_how_do_we_live\%3F. Accessed 2 April 2020.

Eurostat. 2017a. "People in the EU - statistics on an ageing society - statistics explained." http://ec.europa.eu/eurostat/statistics-explained/index.php?title=People_ in_the_EU_-_statistics_on_an_ageing_society. Accessed 2 April 2020.

Eurostat. 2017b. "Tourism statistics." http://ec.europa.eu/eurostat/statistics-explained/ index.php/Tourism_statistics_-_participation_in_tourism\#Participation_in_ tourism_was_significantly_lower_among_persons_aged_65_and_over. Accessed 20 June 2018.

Giesel, Flemming, and Katja Köhler. 2015. "How poverty restricts elderly Germans' everyday travel." In European Transport Research Review 7, no. 15, 1-9. https://doi.org/10.1007/s12544-015-0164-6.

Hounsell, Nick B., Birendra P. Shrestha, Mike McDonald, and Alan Wong. 2016. "Open data and the needs of older people for public transport information.” In Transportation Research Procedia 14 (January). 4334-4343. https://doi. org/10.1016/J.TRPRO.2016.05.355.

Institute for Mobility Research. 2013. Mobility Y. The Emerging Travel Patterns of Generation Y. Institute for Mobility Research. Munich. https://www.ifmo.de/ files/publications_content/2013/ifmo_2013_Mobility_Y_en.pdf. Accessed 13 June 2018.

McDonald, Mike, Nick Hounsell, Alan Wong, Birendra Shrestha, Niccolò Baldanzini, Avinash P. Penumaka, and Ingrid Hendriksen. 2012. GOAL project. European Commission. https://www.southampton.ac.uk/engineering/research/projects/ goal_growing_older_staying_mobile.page\#project_overview\%0A. Accessed 2 April 2020.

McDonald, Mike, Nick Hounsell, Alan Wong, Birendra Shrestha, Niccolò Baldanzini, Avinash P. Penumaka, and Ingrid Hendriksen. 2013. "Transport needs for an ageing society - action plan.” European Commission. https://trimis.ec.europa. eu/sites/default/files/project/documents/20140115_095617_32515_Action_Plan_. Transport_Needs_of_an_Aging_Society.pdf. Accessed 2 April 2020.

Metz, David. 2013. "Peak car and beyond. The fourth era of travel." In Transport Reviews 33, no. 3, 255-270. https://doi.org/10.1080/01441647.2013.800615.

OECD. 2018. "Elderly population (indicator)." https://data.oecd.org/pop/elderlypopulation.htm\#indicator-chart. Accessed 2 April 2020.

Samek Lodovici, Manuela, Flavia Pesce, Patrizia Malgeri, Silvia Maffii, and Caterina Rosa. 2012. "The role of women in the Green Economy - the issue of mobility.” Policy Department C: Citizens' Rights and Constitutional Affairs European Parliament. Brussels. http://www.europarl.europa.eu/RegData/etudes/ note/join/2012/462453/IPOL-FEMM_NT(2012)462453_EN.pdf. Accessed 14 June 2018.

Shrestha, Birendra P., Alexandra Millonig, Nick B. Hounsell, and Mike McDonald. 2017. "Review of public transport needs of older people in European context." In Journal of Population Ageing 10, no 4: 343-361. https://doi.org/10.1007/ s12062-016-9168-9.

Transport for London. 2014. "Understanding the travel needs of London's diverse communities. A summary of existing research." http://content.tfl.gov.uk/ understanding-the-travel-needs-of-london-diverse-communities.pdf. Accessed 13 June 2018. 


\section{Vasco Reis and André Freitas}

Verhaegen, Paul. 1995. "Liability of older drivers in collisions." In Ergonomics 38, no 3, 499-507. https://doi.org/10.1080/00140139508925121

WHO. 2016. "Definition of an older person. Proposed working definition of an older person in Africa for the MDS Project." In World Health Organisation. https:// www.who.int/healthinfo/survey/ageingdefnolder/en/. Accessed 2 April 2020.

Wisch, Marcus, Elvir Vukovic, Roland Schäfer, David Hynd, Adam Barrow, Rahul Khatry et al. 2017. "Road traffic accidents involving the elderly and obese people in Europe incl. investigation of the risk of injury and disabilities." http://www. seniors-project.eu/download/public-files/public-deliverables/SENIORS_D1.2_ Crash_data_Hospital_statistics_DRAFT.pdf. Accessed 2 April 2020.

Zmud, Johanna, Lisa Green, Tobias Kuhnimhof, Scott Le Vine, John Polak, and Peter Phleps. 2017. "Still going ... and going: The emerging travel patterns of older adults." https://www.bmwgroup.com/content/dam/grpw/websites/bmwgroup com/company/downloads/en/2017/2017-BMW-Group-IFMO-Publication. September.pdf. Accessed 2 April 2020. 